\title{
Systematic Relationship between Sr Content and the Lattice Constants in Sr Substituted Hydroxyapatite Thin Films
}

\author{
Hiroaki Nishikawa1 ${ }^{*}$, Ayaka Saito², Akiko Miyake³, Yuichiro Tashiro3 ${ }^{3}$, Yoshiya Hashimoto ${ }^{4}$ \\ ${ }^{1}$ Faculty of Biology-Oriented Science and Technology, Kindai University, Kinokawa, Japan \\ ${ }^{2}$ Graduate School of Biology-Oriented Science and Technology, Kindai University, Kinokawa, Japan \\ ${ }^{3}$ Department of Removable Prosthodontics and Occlusion, Osaka Dental University, Hirakata, Japan \\ ${ }^{4}$ Department of Biomaterials, Osaka Dental University, Hirakata, Japan \\ Email: *nishik32@waka.kindai.ac.jp
}

How to cite this paper: Nishikawa, $\mathrm{H}$. Saito, A., Miyake, A., Tashiro, Y. and Hashimoto, Y. (2017) Systematic Relationship between $\mathrm{Sr}$ Content and the Lattice Constants in Sr Substituted Hydroxyapatite Thin Films. Journal of Crystallization Process and Technology, 7, 1-10.

https://doi.org/10.4236/jcpt.2017.71001

Received: December 5, 2016

Accepted: January 17, 2017

Published: January 20, 2017

Copyright (C) 2017 by authors and Scientific Research Publishing Inc. This work is licensed under the Creative Commons Attribution International License (CC BY 4.0).

http://creativecommons.org/licenses/by/4.0/

\begin{abstract}
To increase the biocompatibility of hydroxyapatite $(\mathrm{HA}), \mathrm{Ca}_{10}\left(\mathrm{PO}_{4}\right)_{6}(\mathrm{OH})_{2}$, the $\mathrm{Sr}$ substitution of $\mathrm{Ca}$ into the $\mathrm{HA}$ structure was effected to yield $\mathrm{Ca}_{10-x} \mathrm{Sr}_{x}\left(\mathrm{PO}_{4}\right)_{6}(\mathrm{OH})_{2}(\mathrm{Sr}-\mathrm{HA})$. For medical and dental applications, it is important that $\mathrm{Sr}-\mathrm{HA}$ is prepared as a thin film so that the $\mathrm{Sr}$ fully substitutes the $\mathrm{Ca}$ sites in the HA structure and does not form segregated impurities consisting of $\mathrm{Sr}$ compounds. If the segregated $\mathrm{Sr}$ forms different amounts of different impurities, the dissolution of the $\mathrm{Sr}$ into the living body will not be reproducible across different samples. To confirm the $\mathrm{Sr}$ substitution into the Ca site in the HA structure, the systematic variation in the lattice constants of the Sr-HA with $\mathrm{Sr}$ content was evaluated as the first step. The $a$ - and $c$-axis lengths were found to exhibit a linear relationship with the Sr content for six samples with different $\mathrm{Sr}$ contents, indicating that the prepared Sr-HA thin films likely possessed partial Sr substitution into the Ca sites of the HA structure. This result is an important first step in the accurate evaluation of the biological effects of Sr-HA thin films.
\end{abstract}

\section{Keywords}

Sr Substituted Hydroxyapatite, X-Ray Diffraction, Lattice Constant, Pulsed Laser Deposition Technique

\section{Introduction}

Hydroxyapatite (HA), $\mathrm{Ca}_{10}\left(\mathrm{PO}_{4}\right)_{6}(\mathrm{OH})_{2}$, is widely applied as a component of medical and dental devices [1] [2] [3] [4] [5] owing to its excellent bone repairing ability via activating osteoblasts. However, it has been pointed out that the 
main component of bones and teeth, which is called biological apatite (BA), is not stoichiometrically-pure HA but variously-substituted HA. Recently, BA and various artificial substituted apatites have been studied from a rapid bone repair point of view [6] [7] [8] [9]. To develop an excellent apatite material for use in medical and dental devices, the most effective dopant concentration for substituted apatite should be investigated, and our attention has been attracted to $\mathrm{Sr}$ substituted HA ( $\mathrm{Sr}-\mathrm{HA}), \mathrm{Ca}_{10-} \mathrm{Sr}_{x}\left(\mathrm{PO}_{4}\right)_{6}(\mathrm{OH})_{2}$. While the amount of $\mathrm{Sr}$ in BA is very small, it is understood to have significant effects on the mineralization of bone tissue [10] [11] as a treatment material for osteoporosis [12]. These functions of Sr likely derive from its excellent ability to activate osteoblasts and deactivate osteoclasts. On the basis of this knowledge regarding the function of $\mathrm{Sr}$ on bone repair, the preparation of Sr-HA has been studied extensively [8] [13] [14] [15] [16]. In these studies, it has been found that $\mathrm{Sr}$ can be substituted into $\mathrm{Ca}_{10-x} \mathrm{Sr}_{x}\left(\mathrm{PO}_{4}\right)_{6}(\mathrm{OH})_{2}$ by up to $x=10$ [8] [13] [14] [15], and that the $a$ - and $c$-axis lengths increase linearly with $x$ [8] [13]. Progress in the preparation of bulk SrHA, however, has not been sufficient to successfully apply these materials into medical and dental devices. One of the most suitable ways to use Sr-HA in medical and dental devices is to coat it as a thin film on the surface of devices, owing to the fact that bulk Sr-HA cannot withstand the variety of stresses in living bodies owing to its poor mechanical strength [15].

So far, several pioneer studies have reported the preparation of Sr-HA thin films [14] [15] [16]. Although these reports are very important milestones for the practical application of Sr-HA thin films, it has not been confirmed that the $\mathrm{Sr}^{2+}$ has been substituted into the $\mathrm{Ca}^{2+}$ site in the HA structure, and is not, instead, present in any form including segregated impurity phases comprising $\mathrm{Sr}$ compounds. If the segregated $\mathrm{Sr}$ forms into different amounts of different impurities, the dissolution of the Sr into the living body will not be reproducible across different samples. As the first step to confirm the $\mathrm{Sr}^{2+}$ substitution into the $\mathrm{Ca}^{2+}$ site in the HA structure, the systematic relationship between the Sr content and the $a$ - and $c$-axis lengths must be studied to determine a relatively low and appropriate Sr amount (Note that excess Sr may cause hypocalcaemia [17], etc., owing to the low absolute amount of $\mathrm{Sr}$ in the living body). Such studies have already been reported for bulk Sr-HA, as mentioned above [8] [13], however, there are no clear reports for the Sr-HA thin films. While Pereiro et al. seem to report the systematic variations of the $a$-and $c$-axis lengths as a function of the Sr content for the Sr-HA thin films [16], this result is insufficient. This is because the targets for pulsed laser deposition (PLD) used as the source for these $\mathrm{Sr}-\mathrm{HA}$ thin films, were made by mixing stoichiometric $\mathrm{HA}$ powder and $\mathrm{SrCO}_{3}$ powder in the proper ratio. As a result, the amount of $\left(\mathrm{CO}_{3}\right)^{2-}$ in the obtained films varied with the $\mathrm{Sr}$ content. Furthermore, the $(\mathrm{Ca}+\mathrm{Sr}) / \mathrm{P}$ value also varied with the $\mathrm{Sr}$ content in this $\mathrm{Sr}-\mathrm{HA}$ target preparation method. If it is possible that the origin of the variation of the $a$-and $c$-axis lengths was the variation of the $\left(\mathrm{CO}_{3}\right)^{2-}$ content or the $(\mathrm{Ca}+\mathrm{Sr}) / \mathrm{P}$ value, it cannot be conclusively stated that the $\mathrm{Sr}^{2+}$ substitutes the $\mathrm{Ca}^{2+}$ site in the HA structure. 
In this study, we report the systematic variation of the lattice constants with the $\mathrm{Sr}$ content for $\mathrm{Sr}-\mathrm{HA}$ thin films prepared using PLD for a region comprising a relatively low $\mathrm{Sr}$ amount of $x \leq 1.0$ (the upper limit is $10 \%$ of the Ca sites on the HA structure). The lattice constants of the films were determined using $\mathrm{X}$-ray diffraction (XRD) measurements. If the $\mathrm{Sr}$ is properly substituted into $\mathrm{Ca}$ sites, the lattice constants increase proportionally with $x$. Verifying a certain amount of the substitution of Sr into Ca sites is an important step towards successfully applying Sr-HA into medical and dental devices before its biological properties can be examined.

\section{Experimental Details}

All of the Sr-HA thin films prepared in this work were deposited on a pure Ti substrate disk (Sumitomo Metals Naoetsu, Japan, purity $\geq 99.427 \%$ ) with a diameter and thickness of 15 and $0.5 \mathrm{~mm}$, respectively. The as-received Ti substrate disk was polished to a mirror finish using the procedure described in a previous paper [18]. Pulsed laser deposition using a $\mathrm{KrF}$ excimer laser (Lambda Physik; COMPex 102, $\lambda=248 \mathrm{~nm}$ ) was employed to prepare the Sr-HA thin films at a fluence of $2.8 \mathrm{~J} / \mathrm{cm}^{2}$ and a repetition rate of $10 \mathrm{~Hz}$. The PLD target was a hand-made pellet prepared using the following method: Commercially-available powders of $\mathrm{CaCO}_{3}, \mathrm{Ca}_{3}\left(\mathrm{PO}_{4}\right)_{2}$, and $\mathrm{SrCO}_{3}$ were weighed in the appropriate stoichiometric ratio and mixed and crushed. Here, the appropriate stoichiometric ratio means that the atomic ratio of $\mathrm{Sr} /(\mathrm{Ca}+\mathrm{Sr})(\times 10)($ i.e., $x)$ was $0,0.5$ and 1.0 while that of $(\mathrm{Ca}+\mathrm{Sr}) / \mathrm{P}$ was maintained at $10 / 6$ (approximately 1.67$)$. To represent the $\mathrm{Sr}$ content, we do not use the value $\mathrm{Sr} /(\mathrm{Ca}+\mathrm{Sr})$, but instead we use 10 times that value because the value $\mathrm{Sr} /(\mathrm{Ca}+\mathrm{Sr})(\times 10)$ is equal to the $\mathrm{Sr}$ content $(x)$ in the chemical formula of the Sr-HA, $\mathrm{Ca}_{10-x} \mathrm{Sr}_{x}\left(\mathrm{PO}_{4}\right)_{6}(\mathrm{OH})_{2}$. In the case of $\mathrm{Ca}_{10-x} \mathrm{Sr}_{x}\left(\mathrm{PO}_{4}\right)_{6}(\mathrm{OH})_{2}$, the atomic ratio of the $\mathrm{Ca}$ and the $\mathrm{Sr}$ contents are $10-x$ and $x$, respectively. Therefore, the value $\mathrm{Sr} /(\mathrm{Ca}+\mathrm{Sr})$ itself is not equal to $x$ but to $x /[(10-x)+x]=x / 10$, and thus the value $\mathrm{Sr} /(\mathrm{Ca}+\mathrm{Sr})(\times 10)$ is employed to represent the Sr content in this paper. The mixture was then molded in a $\phi 20$ $\mathrm{mm}$ die at a pressure of $100 \mathrm{kgf} / \mathrm{cm}^{2}$ for $10 \mathrm{~min}$. The pellet was sintered at $800^{\circ} \mathrm{C}$ for $10 \mathrm{~h}$, and was then crushed, remolded, and sintered again under the same conditions. The prepared target was placed into the PLD chamber (base pressure of approximately $10^{-1} \mathrm{~Pa}$ ) at a distance of $38 \mathrm{~mm}$ from the substrate. The temperature of the Ti substrate was $400^{\circ} \mathrm{C}$ during the growth, as monitored using an optical pyrometer (Chino; IR-CI2SCF, $400^{\circ} \mathrm{C}-900^{\circ} \mathrm{C}$ ). An $\mathrm{O}_{2}+\mathrm{H}_{2} \mathrm{O}$ gas mixture was generated by bubbling pure $\mathrm{O}_{2}$ gas though a distilled water bath, which was then introduced into the growth chamber at a pressure of $50 \mathrm{~Pa}$. All of the produced thin films were approximately $450 \mathrm{~nm}$ thick, as measured using a stylus surface profiler (ULVAC; Dektak 150). The thin films were post annealed at $500^{\circ} \mathrm{C}$ for $10 \mathrm{~h}$ in a quartz tube inside a furnace, where the $\mathrm{O}_{2}+\mathrm{H}_{2} \mathrm{O}$ mixture was passed through the quartz tube during the annealing. The crystal structure and the lattice parameters of the thin films were evaluated with an XRD apparatus (Rigaku; Ultima IV) using conventional $2 \theta / \theta$ measurements. Errors in the $\theta$ 
value were considered in this experiment because they occurred easily owing to the slight tilt of the sample surface against the sample holder (the standard of $\theta=$ $\left.0^{\circ}\right)$ of the XRD apparatus. The calibration of the $\theta$ was done using the diffraction peak of the Ti (101) plane (located at $d=0.2243 \mathrm{~nm}$ ) obtained from the substrate. $\mathrm{The} \mathrm{Sr} /(\mathrm{Ca}+\mathrm{Sr})$ and $(\mathrm{Ca}+\mathrm{Sr}) / \mathrm{P}$ ratios of the prepared thin film were measured using X-ray photoelectron spectroscopy (XPS, ULVAC-PHI; PHI Xtool), using measurements of $\mathrm{Ca} 2 \mathrm{p}, \mathrm{Sr} 3 \mathrm{p}$, and P 2 s.

\section{Results and Discussion}

Table 1 lists the XPS results of the $\mathrm{Sr} /(\mathrm{Ca}+\mathrm{Sr})(\times 10)$ and $(\mathrm{Ca}+\mathrm{Sr}) / \mathrm{P}$ ratios obtained for six Sr-HA thin films prepared with different $\mathrm{Sr}$ contents, where the samples A-F were deposited using Sr-HA targets with $x=0.0$ (A, B), 0.5 (C, D), and $1.0(\mathrm{E}, \mathrm{F})$. Figure 1 shows a summary of the XPS results given in Table 1 , where the left vertical axis represents the $\mathrm{Sr} /(\mathrm{Ca}+\mathrm{Sr})$ ratio of the thin films (black circles) and the fitting obtained by the least squares method (black dashed line). Further, the right vertical axis of Figure 1 represents the $(\mathrm{Ca}+\mathrm{Sr}) / \mathrm{P}$ ratio of the thin films (red squares) and the average value of $(\mathrm{Ca}+\mathrm{Sr}) / \mathrm{P}$ for all samples

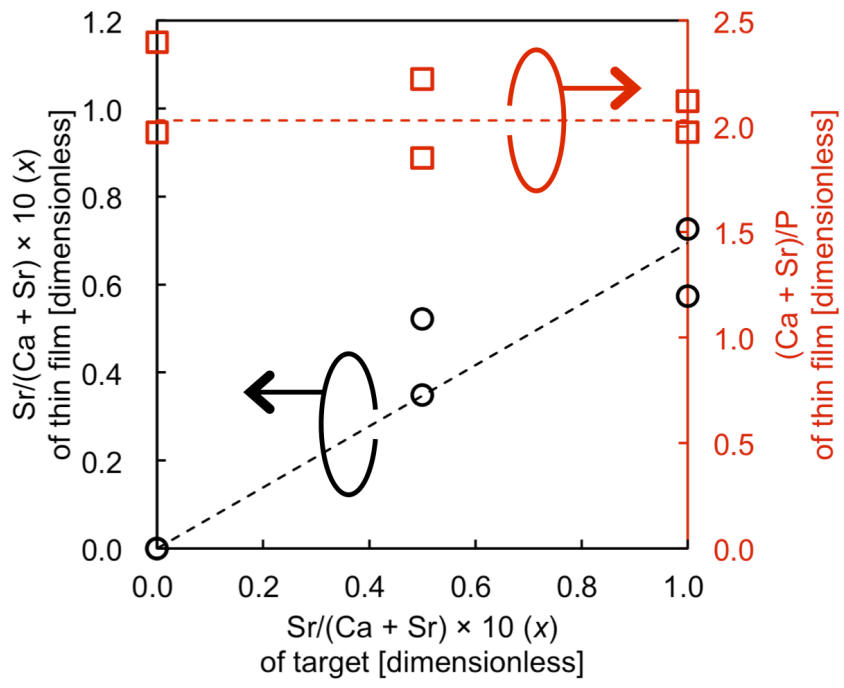

Figure 1. Relationship between $\mathrm{Sr} /(\mathrm{Ca}+\mathrm{Sr})$ (black circles, left vertical axis) and (Ca + $\mathrm{Sr} / \mathrm{P}$ (red squares, right vertical axis) content in the thin films and the $\mathrm{Sr} /(\mathrm{Ca}+\mathrm{Sr}$ ) content in the target.

Table 1. Summary of X-ray photoelectron spectral analysis results for Sr-HA thin films with varying Sr content.

\begin{tabular}{ccc}
\hline Sample & $\mathrm{Sr} /(\mathrm{Ca}+\mathrm{Sr})(\times 10)$ [dimensionless $]$ & $(\mathrm{Ca}+\mathrm{Sr}) / \mathrm{P}[$ dimensionless $]$ \\
\hline A & 0.00 & 2.40 \\
B & 0.00 & 1.97 \\
C & 0.35 & 1.85 \\
D & 0.52 & 2.22 \\
E & 0.57 & 2.12 \\
F & 0.73 & 1.97 \\
\hline
\end{tabular}


(red dashed line). The relationship between the Sr content of the targets and the corresponding thin films was found to be roughly proportional, while the value of $\mathrm{Sr} /(\mathrm{Ca}+\mathrm{Sr})$ of each thin film showed a slight deviation from that of the target. A tendency of Sr defects to exist in PLD-deposited thin films such as these has also been reported in a previous work [16], although the mechanism is not understood. The $(\mathrm{Ca}+\mathrm{Sr}) / \mathrm{P}$ ratios in Figure 1 exhibit some deviation from the stoichiometric value of approximately 1.67 , and it can also be observed that the $(\mathrm{Ca}+\mathrm{Sr}) / \mathrm{P}$ ratio of the thin films is not dependent on the $\mathrm{Sr}$ content of the target and the thin film. However, considering a previous work where we found that the $\mathrm{Sr} /(\mathrm{Ca}+\mathrm{Sr})$ and $(\mathrm{Ca}+\mathrm{Sr}) / \mathrm{P}$ of $\mathrm{Sr}-\mathrm{HA}$ thin films can be highly controlled by the energy distribution of the ablation laser on the target [18] [19], these details are now being studied and the control of the chemical composition of Sr-HA and HA thin films will be reported in a subsequent paper. Judging from these results, the constant deviation of the $\mathrm{P}$ content independent of the $\mathrm{Sr}$ content of the Sr-HA thin film will not affect the present study of the variation of the lattice constants with the Sr content.

Figure 2(a) shows the XRD patterns of Sr-HA thin films deposited on Ti substrates, where the scan conditions used were a sampling step of $0.1^{\circ}$ and as can speed of $4 \% \mathrm{~min}$. The XRD patterns of all samples exhibited peaks attributable to a crystalline HA structure and to $\mathrm{Ti}$, indicating that all of the samples were wellcrystallized in the HA structure without any crystalline impurity phases. Next, the XRD patterns were analyzed to investigate the variation of the lattice constants as a function of the Sr content. If Sr atoms are precisely substituted into $\mathrm{Ca}$ sites, the lattice constants should exhibit a linear relationship with the $\mathrm{Sr}$ content in accordance with Vegard's law. To this purpose, we examined four diffraction peaks from (002), (211), (112) and (300) of the HA structure and the $2 \theta$ values of these peaks were calculated using a least squares method fitting program with a split-type Pseudo-Voigt function. Though the peaks from (102), (202) and (301) were also observed in some of the samples, the fitting program did not recognize all of these peaks in every sample owing to insufficient peak intensity. Figure 2 (b) shows the XRD patterns at $2 \theta=24.0^{\circ}-27.0^{\circ}$ for the (002) peak and $2 \theta=31.0^{\circ}-34.0^{\circ}$ for the (211), (112), and (300) peaks. In obtaining these XRD patterns, the scan was narrower stepwise $\left(0.01^{\circ}\right)$ and the scan speed decreased $\left(0.2^{\circ} / \mathrm{min}\right)$ compared to those in Figure 2(a). All peaks exhibited a rough tendency to shift toward lower diffraction angle with increasing Sr content from sample A and B of $x=0.0$ to $F$ (dashed lines to guide the eye). To quantitatively evaluate the lattice constant variation of the thin films, the relationships between the $\mathrm{Sr} /(\mathrm{Ca}+\mathrm{Sr})$ ratio in Figure 1 and the a-axis (left vertical axis, black circles) and $c$-axis lengths (right vertical axis, red squares) are summarized in Figure 3(a). Using this plot, the curves for the $a$ - and $c$-axis lengths were fitted by the least squares method, whereupon the a-axis length was determined using the average of two calculated values, one from the (300) peak and the other from the (211) and (112) peaks. Similarly, the $c$-axis length was also determined using the average of two calculated values, one from the (002) peak 

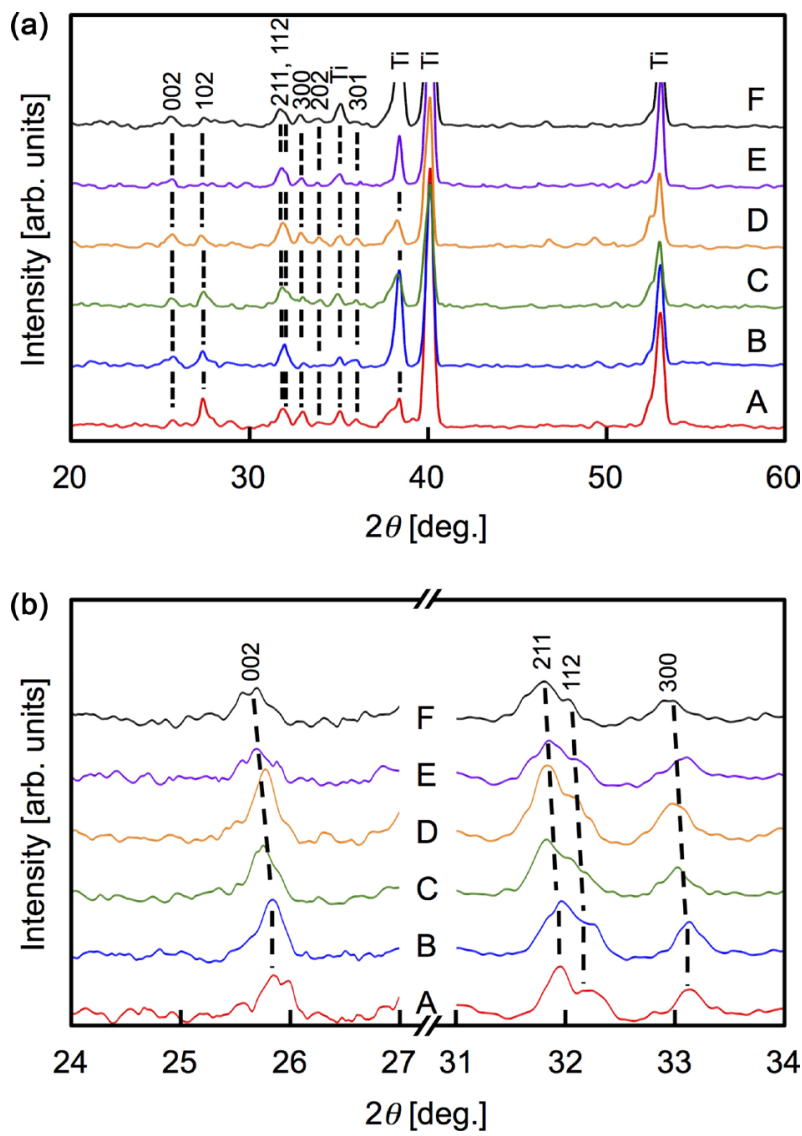

Figure 2. X-ray diffraction patterns of the Sr-HA thin films. (a) Complete $2 \theta$ range for measured diffraction spectra. (b) Shift of the (002), (211), (112), and (300) peaks toward lower $2 \theta$ is observed with higher Sr content in the Sr-HA thin films.

and the other from the (211) and (112) peaks. Figure 3(a) shows that both the $a$ and $c$-axis lengths have roughly linear relationships with the $\mathrm{Sr} /(\mathrm{Ca}+\mathrm{Sr})$ content. The obtained correlation coefficient for the a-axis length was $R=0.911$ with $p<0.05$ and that for the $c$-axis length was $R=0.952$ with $p<0.005$. As described above, the $(\mathrm{Ca}+\mathrm{Sr}) / \mathrm{P}$ ratio was almost comparable for all samples independent of their Sr content. Thus, it can be concluded that the variation in the lattice constants was caused by the substitution of Sr into $\mathrm{Ca}$ sites in the HA structure. To confirm this finding, the relationships between $(\mathrm{Ca}+\mathrm{Sr}) / \mathrm{P}$ in the thin films and the $a$ - and $c$-axis lengths are shown in Figure $3(\mathrm{~b})$. Here, the lattice constants do not exhibit a clear dependence on the $\mathrm{P}$ content of the thin films when considering the least squares method fitting lines $(R=0.494$ and 0.370 for the $a$ - and $c$-axis lengths, respectively). From Figure 3, therefore, the systematic variation in the lattice constants was caused by the variation in the $\mathrm{Sr}$ content and not the $\mathrm{P}$ content.

The correlation coefficients in Figure 3(a) seem to be somewhat lower than the reported values [8] [13]. In this work, the dispersion of the lattice constants from linearity will not be caused by errors of the deviation in the zero point for each sample. This is owing to the fact that the values measured in this study have no sample-dependent systematic errors because the zero points were unified 

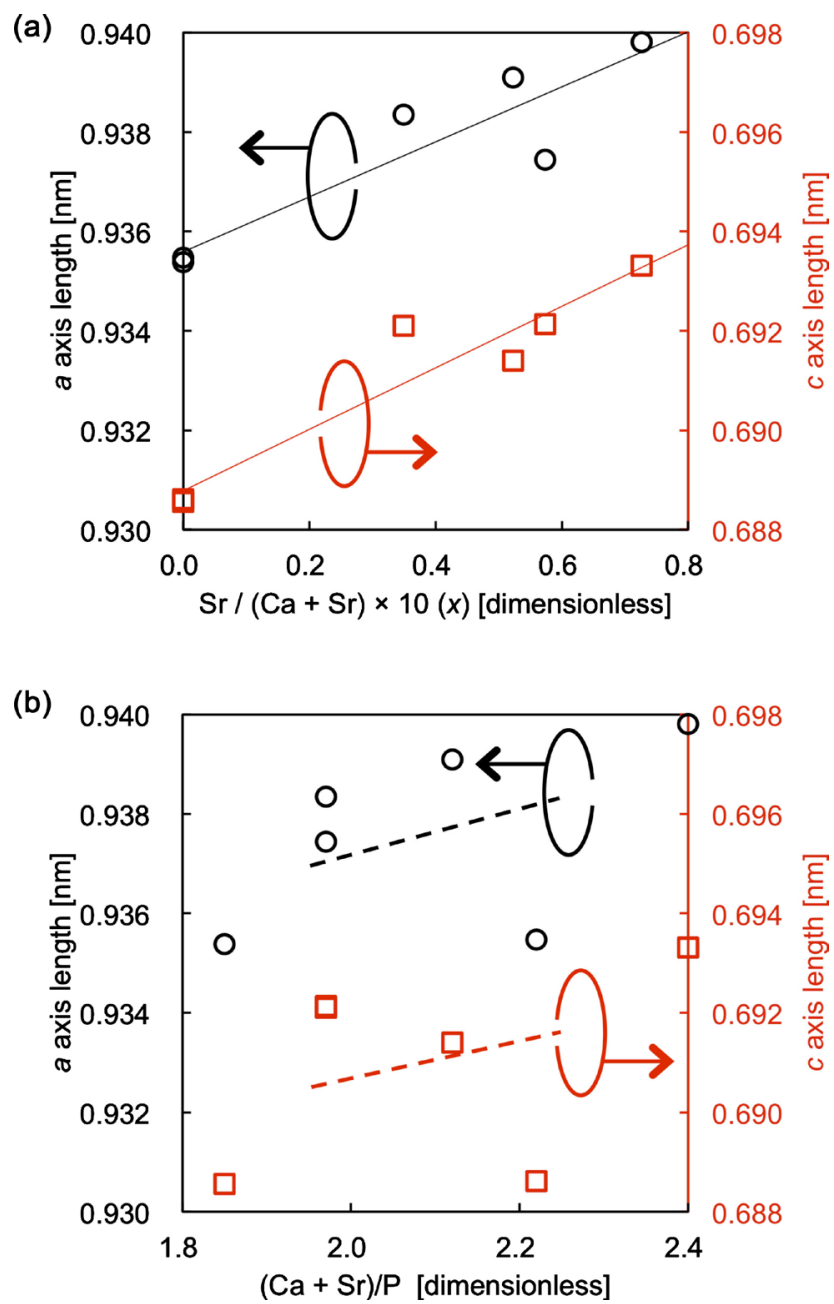

Figure 3. Lattice constants as a function of (a) Sr content and (b) P content in the Sr-HA thin films. Both plots show the lengths of the a-axis (black circles, left vertical axis) and the $c$-axis (red squares, right vertical axis).

with the calibration procedure using the $\mathrm{Ti}$ (101) peak of the substrate for all samples. We will consider if this type of dispersion is reduced with an increasing number of samples. Furthermore, statistical processing will be subsequently needed to determine the Sr content for each sample based on the data measured at several positions on the same sample, while in this study they were measured at only a single position for each sample. The spatial distribution of the $\mathrm{Sr}$ content should also be evaluated for all samples in subsequent studies. In this expanded process, we expect more precise evaluation with a certain error bar for the chemical composition data.

The effect of the presence of an impurity phase contained in the samples should also be discussed. In this study, the XRD results revealed that all of the samples contained no crystalline impurities, so any impurity phases that do exist should be amorphous. The possibility that the samples contain amorphous impurities cannot be ignored owing to the observed deviation of the $\mathrm{P}$ content. If all of the Sr was contained and/or was substituted only in such impurity phases, this implies that the crystal phase of the HA structure was not Sr-HA but only 
the stoichiometrically-pure HA. However, the experimental result exhibits a systematic relationship between the $\mathrm{Sr}$ content and the lattice constants. This result signifies that the Sr must have some effect on the crystal structure of the Sr-HA thin films because the result was not caused by the variation of the $\mathrm{P}$ content herein, as shown in Figure 3(b). In this work, the results are considered as a first approximation that a certain ratio of the $\mathrm{Ca}^{2+}$ site was substituted with the larger $\mathrm{Sr}^{2+}$ in the HA structure, while the absolute substitution ratio cannot be estimated owing to the defect of the $\mathrm{PO}_{4}$, as described above. This means that the absolute values of the lattice constant sherein cannot be compared directly to the reported values [8] [13].

In this study, we have made progress toward eliminating the possibility that the systematic variation of the lattice constants was caused by a variation of the P content, unlike the previous paper [16]. We have three plans to improve these results in subsequent studies.

1) It is necessary to improve the chemical composition of the $\mathrm{P}$ content toward the stoichiometric value of $(\mathrm{Ca}+\mathrm{Sr}) / \mathrm{P}=1.67$ using the technique we have previously reported [18] [19].

2) Fourier transform infrared spectroscopy should be implemented to confirm the $\mathrm{CO}_{3}$ content and to quantify the ratio of the $\mathrm{PO}_{4}$ and the $\mathrm{CO}_{3}$ if the $\mathrm{CO}_{3}$ is present in the samples.

3) The lattice constants and the chemical compositions of the PLD Sr-HA targets were not analyzed in this study. Because the target characteristics can be used as reference data to analyze the results for the Sr-HA thin films, the Sr-HA targets should be analyzed as the bulk Sr-HA.

\section{Conclusion}

To successfully apply Sr-HA in medical and dental devices, the systematic relationship between the $\mathrm{Sr}$ content and the $a$-and $c$-axis lengths must be studied for materials with relatively low amounts of Sr. The Sr-HA thin films prepared using PLD in this work exhibited lattice constants that possessed a roughly linear relationship with their $\mathrm{Sr}$ content, as evaluated by XPS and XRD. This result is considered as a first approximation showing that the $\mathrm{Sr}^{2+}$ substitutes into the $\mathrm{Ca}^{2+}$ site in the HA structure, where more refinement of the results is needed to realize the ultimate goal of the study.

\section{Acknowledgements}

This work was supported in part by grants from the Strategic Research Foundation Grant-Aided Project for Private Universities from the Ministry of Education, Culture, Sports, Science, and Technology, Japan, 2013-2017 (No. S1311045) and the Project Research of the Faculty of Biology-Oriented Science and Technology, Kindai University, 2015-2016 (No. 14-I-3) and 2016 (No. 15-III-32).

\section{References}

[1] Geesink, R.G.T., de Groot, K. and Klein, C.P.A.T. (1987) Chemical Implant Fixation 
Using Hydroxyl-Apatite Coatings. The Development of a Human Total Hip Prosthesis for Chemical Fixation to Bone Using Hydroxyl-Apatite Coatings on Titanium Substrates. Clinical Orthopaedics and Related Research, 225, 147-170.

[2] Klein, C.P.A.T., Patka, P., van der Lubbe, H.B.M., Wolke, J.G.C. and de Groot, K. (1991) Plasma-Sprayed Coatings of Tetracalciumphosphate, Hydroxyl-Apatite, and $\alpha$-TCP on Titanium Alloy: An Interface Study. Journal of Biomedical Materials Research, 25, 53-65. https://doi.org/10.1002/jbm.820250105

[3] McPherson, R., Gane, N. and Bastow, T.J. (1995) Structural Characterization of Plasma-Sprayed Hydroxylapatite Coatings. Journal of Materials Science: Materials in Medicine, 6, 327-334. https://doi.org/10.1007/bf00120300

[4] Yan, W.Q., Nakamura, T., Kawanabe, K., Nishigochi, S., Oka, M. and Kokubo, T. (1997) Apatite Layer-Coated Titanium for Use as Bone Bonding Implants. Biomaterials, 18, 1185-1190. https://doi.org/10.1016/S0142-9612(97)00057-4

[5] Stoch, A., Brożek, A., Kmita, G., Stoch, J., Jastrzebski, W. and Rakowska, A. (2001) Electrophoretic Coating of Hydroxyapatite on Titanium Implants. Journal of Molecular Structure, 596, 191-200. https://doi.org/10.1016/S0022-2860(01)00716-5

[6] Bigi, A., Falini, G., Foresti, E., Gazzano, M., Ripamonti, A. and Roveri, N. (1993) Magnesium Influence on Hydroxyapatite Crystallization. Journal of Inorganic Biochemistry, 49, 69-78. https://doi.org/10.1016/0162-0134(93)80049-f

[7] Kim, T.N., Feng, Q.L., Kim, J.O., Wu, J., Wang, H., Chen, G.C. and Cui, F.Z. (1998) Antimicrobial Effects of Metal Ions $\left(\mathrm{Ag}^{+}, \mathrm{Cu}^{2+}, \mathrm{Zn}^{2+}\right)$ in Hydroxyapatite. Journal of Materials Science: Materials in Medicine, 9, 129-134. https://doi.org/10.1023/A:1008811501734

[8] O'Donnell, M.D., Fredholm, Y., de Rouffignac, A. and Hill, R.G. (2008) Structural Analysis of a Series of Strontium-Substituted Apatites. Acta Biomaterialia, 4, 14551464. https://doi.org/10.1016/j.actbio.2008.04.018

[9] Ergun, C., Webster, T.J., Bizios, R. and Doremus, R.H. (2002) Hydroxyapatite with Substituted Magnesium, Zinc, Cadmium, and Yttrium. I. Structure and Microstructure. Journal of Biomedical Materials Research, 59, 305-311.

https://doi.org/10.1002/jbm.1246

[10] Caverzasio, J. (2008) Strontium Ranelate Promotes Osteoblastic Cell Replication through at Least Two Different Mechanisms. Bone, 42, 1131-1136.

https://doi.org/10.1016/j.bone.2008.02.010

[11] Hurtel-Lemaire, A.S., Mentaverri, R., Caudrillier, A., Cournarie, F., Wattel, A., Kamel, S., Terwilliger, E.F., Brown, E.M. and Brazier, M. (2009) The Calcium-Sensing Receptor Is Involved in Strontium Ranelate-Induced Osteoclast Apoptosis. The Journal of Biological Chemistry, 284, 575-584. https://doi.org/10.1074/jbc.M801668200

[12] Reginster, J.Y. (2009) Strontium Ranelate in Osteoporosis. Current Pharmaceutical Design, 8, 1907-1916. https://doi.org/10.2174/1381612023393639

[13] Bigi, A., Boanini, E., Capuccini, C. and Gazzano, M. (2007) Strontium-Substituted Hydroxyapatite Nanocrystals. Inorganica Chimica Acta, 360, 1009-1016.

https://doi.org/10.1016/j.ica.2006.07.074

[14] Capuccini, C., Torricelli, P., Sima, F., Boanini, E., Ristoscu, C., Bracci, B., Socol, G., Fini, M., Mihailescu, I.N. and Bigi, A. (2008) Strontium-Substituted Hydroxyapatite Coatings Synthesized by Pulsed-Laser Deposition: In Vitro Osteoblast and Osteoclast Response. Acta Biomaterialia, 4, 1885-1893. https://doi.org/10.1016/j.actbio.2008.05.005

[15] Ozeki, K., Goto, T., Aoki, H. and Masuzawa, T. (2014) Characterization of Sr-Substituted Hydroxyapatite Thin Film by Sputtering Technique from Mixture Targets of 
Hydroxyapatite and Strontium Apatite. Bio-Medical Materials and Engineering, 24, 1447-1456.

[16] Pereiro, I., Rodríguez-Valencia, C., Serra, C., Solla, E.L., Serra, J. and González, P. (2012) Pulsed Laser Deposition of Strontium-Substituted Hydroxyapatite Coatings. Applied Surface Science, 258, 9192-9197. https://doi.org/10.1016/j.apsusc.2012.04.063

[17] Morohashi, T., Sano, T. and Yamada, S. (1994) Effects of Strontium on Calcium Metabolism in Rats: I. A Distinction between Pharmacologic and Toxic Doses. The Japanese Journal of Pharmacology, 64, 155-162. https://doi.org/10.1254/jjp.64.155

[18] Nishikawa, H. and Yoshikawa, R. (2015) Controlling the Chemical Composition of Hydroxyapatite Thin Films Using Pulsed Laser Deposition. Transactions of the Materials Research Society of Japan, 40, 111-114. https://doi.org/10.14723/tmrsj.40.111

[19] Nishikawa, H., Hasegawa, T., Miyake, A., Tashiro, Y., Hashimoto, Y., Blank, D.H.A. and Rijnders, G. (2016) Relationship Between the Ca/P Ratio of Hydroxyapatite Thin Films and the Spatial Energy Distribution of the Ablation Laser in Pulsed Laser Deposition. Materials Letters, 165, 95-98. https://doi.org/10.1016/j.matlet.2015.11.115

Submit or recommend next manuscript to SCIRP and we will provide best service for you:

Accepting pre-submission inquiries through Email, Facebook, LinkedIn, Twitter, etc. A wide selection of journals (inclusive of 9 subjects, more than 200 journals) Providing 24-hour high-quality service User-friendly online submission system Fair and swift peer-review system Efficient typesetting and proofreading procedure Display of the result of downloads and visits, as well as the number of cited articles Maximum dissemination of your research work

Submit your manuscript at: http://papersubmission.scirp.org/ Or contact jcpt@scirp.org 